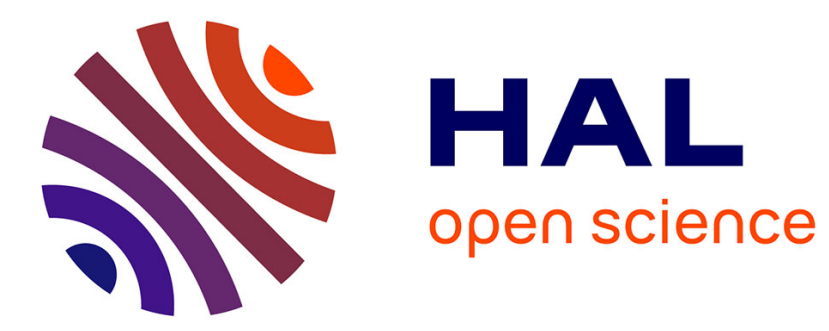

\title{
Patère et casseroles en bronze, découvertes près de Chalon-sur-Saône
}

\author{
Louis Armand-Calliat
}

\section{To cite this version:}

Louis Armand-Calliat. Patère et casseroles en bronze, découvertes près de Chalon-sur-Saône. Gallia - Fouilles et monuments archéologiques en France métropolitaine, 1949, 7 (2), pp.233-235. 10.3406/galia.1949.2137 . hal-01920755

\section{HAL Id: hal-01920755 \\ https://hal.science/hal-01920755}

Submitted on 27 Feb 2020

HAL is a multi-disciplinary open access archive for the deposit and dissemination of scientific research documents, whether they are published or not. The documents may come from teaching and research institutions in France or abroad, or from public or private research centers.
L'archive ouverte pluridisciplinaire HAL, est destinée au dépôt et à la diffusion de documents scientifiques de niveau recherche, publiés ou non, émanant des établissements d'enseignement et de recherche français ou étrangers, des laboratoires publics ou privés.

\section{(이) $\$$}

Distributed under a Creative Commons Attribution - NonCommercial - NoDerivatives| 4.0 


\section{NOTES ET INFORMATIONS}

\section{NOTES}

PATERE ET CASSEROLES EN BRONZE, DÉCOUVERTES PRÈs DE CHAION-STR-SAONE

Quelques trouvailles faites en 19:4 et 1948 dans les sables ou dans les berges de la Saòne aux abords de Chalon viennent de rampner l'atlention sur les vases métalliques que l'on a découverts si fréquemment près de cetle ville, contre important de diffusion et probablement de production pour l'industrie gallo-romaine du bronze.

Il s'agit tout d'abord d'une patère (fig. la) en plaque miner, mise au jour à proximité du petit port d'ouroux en 1948. Iongue de $0^{\mathrm{m}}, 29$, large de $0^{\mathrm{m}}, 135$, elle possède un manche plat, ajouré, décoré de ciselures au trait, dessinant en haut deux têtes de rrgne réunies par une sorte de bandelette disposée triangulairement. Plus bas, se voient deux feuilles très stylisées et onze cercles oculés. Par sa forme générale et par son ornementation ajourcee, rette poignée s'apparente étroitement à celle de la patère de la collection Millon 1 , recueillie, elle aussi, près de Chalon ct que J. Déchclette, en s'appuyant sur les recherches de Willers", datait de l'époque flavienne. Quant aux motifs traités ici - les

(1) DÉcinlette, La collection .Villon, Paris, 1913, p. 259 et pl. XLV, no 3.

(2) WuLcrs, Bronzeindustrie ron Capua und von Niedergermanen, 190\%, p. 79 et pl. VII, 13. protomís de cygne et les cercles oculés - ce sont de vieux thèmes solaires dont l'origine remonte à la préhistoire et qui pourraient avoir ici, sur un objet présumé cultuel, une portée religieuse, si leur emploi généralisé à l'époque romaine ne les avait réduits le plus souvent à un ròle purement décoratif. Nous savons pourtant que le cygne était resté l'altribut d'Apollon et de certaines divinités thermales ${ }^{3}$. Quoiqu'il en soit, il est regrettable que le bassin de cette patère, aujourd'hui conservée au llusée de Chalon, ait subi plusieurs déchirures, dues à la minecur et à la fragilité du métal utilisé

Quelques mois aupararant, était ret:rée des berges de la Saòne, près du gué d'Allériot, à 3 kil. au nord de Chalon, une casserole en bronze (fig. 1b), également de haute époque, mais fondue et, par suite, de fabrication plus lourde. Son bassin, terminé au tour, est étamś a l'intérieur. Sur la poignée, percée d'un trou de suspension, a été tracée une sorte de hampe cisclée en creux, décor que complètent des arabesques en pointillé. On distingue enfin très nettement l'estampille rectiligne du bronzier Florius : FLORIVS $F$ (ecit), marque qui ne figure pas dans les tomes XII et XIII du Corpus.

Celte casserole d'Allériot, recueillie par

(3) DÉchelette, Mamuel, t $^{\text {re }}$ éd., t. II, p.

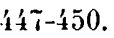




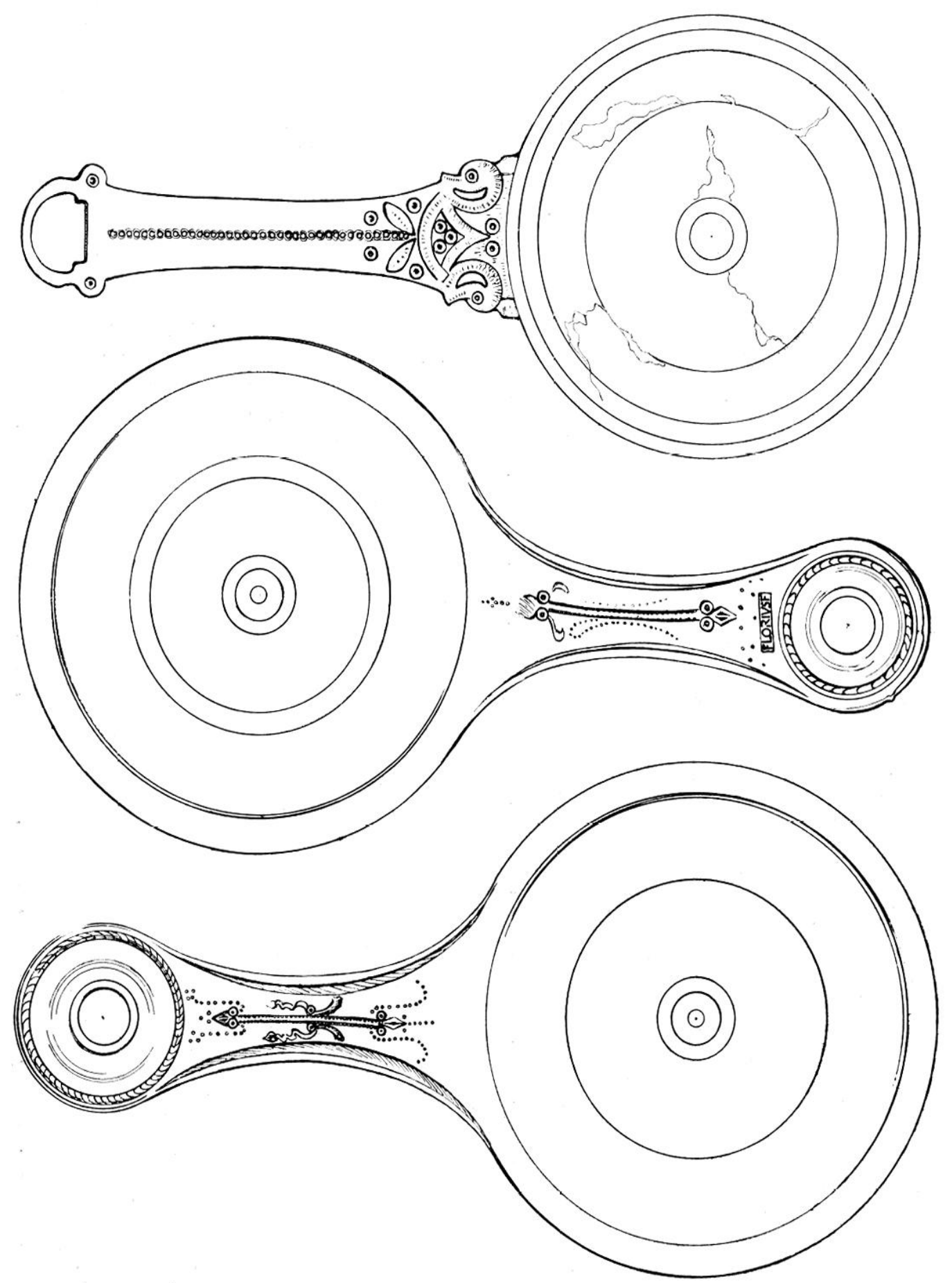

Fig. 1. - $a$ ) en haut : patère trouvée dans la Saône; $b$ ) au milieu : casserole signée Florius; c) en bas : casserole du Musée de Châlon-sur-Saône. 
un collectionneur chalomnais II. Royet. a exactement la même dimension $(0$ m.295 $\dot{x} 0^{\mathrm{m}}, 15 \overline{5}$ ) (gu'une casserole du Musée de Chalon (fig. lo), trouréc dans la saine près du même lieu en 185'́, au cours de dragages ( $n^{\circ}$ 423 du catalogue récent). Cette dernière pièce n'est pas signée; mais non sculement elle offre la même largeur, la même longueur, la mème forme générale, mais elle présente sur son manche un motif tout a fait comparable et traité avec la même technique: ciselure all trait, complétée par des spires au pointillé. Ce qui est plus frappant encore, c'est que la hampe centrale, qui devait olre recliligne, oftre, sur l'un et l'autre ustensile, le mème defaut: une légère torsion à droite. Yous inclinerons volontirs à penser que les deux pièces ont un auteur commun ct sortent de l'alelier de Florius ou hien que l'une a cité directement imitée de l'autre.

Déjà, à propos d’une casserole draguće dans la saòne, à la Truchère, près de Tournus et signée Draccius, Héron de villefosice t avait fait des rapprobliements aver des auvres de cet industriel. découvertes tant dans la banlieue lyonnaise (à Villeurbanne, à Décines-Charpieu) qu’à J ̣oon même et en Ilàconnais. Il en avait conclu que Dracius "devait ètre établi à Iyon ou à proximité de celte ville".

Il serait certes imprudent d'émettre une pareille conjecture à propos de Florius et de tenir ce bronzicr pour Chalonnais. Mais il est certain que la Saòne a fourni près de Cabillonum un nombre considérable de vases métalliques; le Musce Denon, à lui seul, en conserve 55 ayant cette origine et datant de l'époque gallo-romaine', bien qu'il n'ait recueilli qu'une faible partie des découvertes.

(4) Bull. archéol. du Comité, 1917, p. CI.

(5) Cr. Catalogue de 1950 , p. 49-53. Il faut ajouter a ce chiffre 16 vases gaulois.
I'aulrẹ part, nous avons précédemment insisté sur un type de clef à manche de bronze en forme de main féminine et qui, rare ailleurs, est fréquent en Saôneet-Ioire. C'est un modèle régional. L'abondance toule particulière des petites statuettes de métal en Mâconnais et surtout en Chalonnais n'est pas moins suggestive 6. Cel ensemble de constatations nous incitc à penser, avec X. Albert Grenicr ${ }^{7}$, que Chalon ne fut pas seulement, grâce à son port, un centre commercial de diffusion pour les pièces d'orfévrerie et les bronzes méridionaux acheminés par la Saòne, mais aussi un centre de fabrication. Celte ville, située sur la route du plomb et de l'ćtain et peu éloignée de mines de cuivre, était bien placée pour exporter ses produits Aux temps mérovingiens, l'activité singulière et le style " romain " de l'atelier monétaire chalonnais, de même que l'originalitó des pieces dorferrerie ou de damasquinure 8 , retrouvées dans un rayon de 30 kilomètres autour d'elle, entre Charnaylis-Chalon et Tournus, nous semblent les indices de l'utilisation, à l'époque barbare, d'une main d'curre gallo-romainc localc, trìs ancienne et fort expérimentie dans la toreutique.

\section{Armand-Caldint.}

(b) Environ 200 bronzes, dont 80 pour le seul arrondissement de Chalon.

(a) A. Grexiler, Rev. Jit. anc., 1938, p. 411.

(8) M. E. SALIN, La civilisation mérotingien. ne..., Paris 1950, pp. 240 et 355, cherche «au Nord des Alpes». entre "Lron et Genève», les aleliers qui fabriquaient les plaques de bronze de Daniel el de l'hippogriffe, ainsi que les fibules rondes apparentées aux types italo-lombards, à la fin du VI et all VII siècle. Or. sous les règnes de Gontran $(561-593)$ et de son successeur 'l'hierry (596-613), (halon fut la résidence des souverains de Bourgogne dont le royaume comprit un inslant, avec Lyon, « les deux lier's de la Gaule », (1. KuElNclacsz, llist. de Bourgogne, 1924, p. 47, 48 et 53). Cf. A. Bianchet, Manuel de num., I, pp. 217, 233 el 268-269. 